\title{
Rituximab and risk of COVID-19 infection and its severity in patients with MS and NMOSD
}

Sara Esmaeili, ${ }^{1,2,3}$, Mohammad Hossein Abbasi 1,2,3, Meysam Abolmaali³, Mohammad Mojtahed ${ }^{2,3}$, Seyedeh Niloufar Rafiei Alavi ${ }^{3}$, Sevim Soleimani ${ }^{4}$, Mahisa Mokhtari ${ }^{3}$, Jaber Hatam ${ }^{5}$, Samaneh Tanhapour Khotbehsara ${ }^{3}$, Mohammad Reza Motamed ${ }^{3}$, Mohammad Taghi Joghataei ${ }^{1,2}$, Zahra Mirzaasgari $^{3^{*}}$ and Mehdi Moghaddasi ${ }^{3}$

\begin{abstract}
Background: Choosing a safe disease modifying therapy during the COVID-19 pandemic is challenging. This case series study was conducted to determine the incidence rate and the course of Covid-19 infection in MS/NMOSD patients treated with Rituximab.

Methods: In this study, we designed a web-based questionnaire. Baseline information such as patient- reported walking disability, total number of Rituximab infusions received, delayed injections, occurrence of any relapse, and the use of corticosteroids during the pandemic were collected. Also, information regarding the Covid-19 pandemic such as adherence to self-isolation, any recent exposure to an infected individual and the presence of suggestive symptoms were collected. In case of positive test results, patients were grouped into 2 categories; mild to moderate and seriously ill and outcomes were evaluated as favorable (improved/ discharged) and unfavorable (expired).
\end{abstract}

Results: Two hundred fifty-eight patients with Multiple Sclerosis were enrolled in this study, 9 of the subjects (3.4\%) were confirmed positive for Covid-19, five of which required hospitalizations (55.5\%), two patients required ICU admission (22.2\%) and 2 two patients died (22.2\%). None of these patients ever mentioned using corticosteroids during the pandemic. In comparison to MS patients who were not receiving disease modifying therapy (DMT), our study indicated a higher incidence of Covid-19 infection, higher ratio of serious illness and a higher fatality ratio.

Conclusions: Rituximab seems not to be safe enough during the pandemic.

Keywords: COVID-19, Disease modifying therapy, Multiple sclerosis, MS, Neuromyelitis Optica, NMO, Rituximab

\footnotetext{
* Correspondence: Zahra.Mirzaasgari@gmail.com

${ }^{3}$ Department of Neurology, Iran University of Medical Sciences, Tehran, Iran

Full list of author information is available at the end of the article
}

(C) The Author(s). 2021 Open Access This article is licensed under a Creative Commons Attribution 4.0 International License, which permits use, sharing, adaptation, distribution and reproduction in any medium or format, as long as you give appropriate credit to the original author(s) and the source, provide a link to the Creative Commons licence, and indicate if changes were made. The images or other third party material in this article are included in the article's Creative Commons licence, unless indicated otherwise in a credit line to the material. If material is not included in the article's Creative Commons licence and your intended use is not permitted by statutory regulation or exceeds the permitted use, you will need to obtain permission directly from the copyright holder. To view a copy of this licence, visit http://creativecommons.org/licenses/by/4.0/ The Creative Commons Public Domain Dedication waiver (http://creativecommons.org/publicdomain/zero/1.0/) applies to the data made available in this article, unless otherwise stated in a credit line to the data. 


\section{Introduction}

SARS-CoV-2 also known as Coronavirus disease COVID-19 has become a public health emergency of international concern [1], accounting to numerous reported neurological manifestations [2]. Smoking, older age ( $>60$ years old), comorbidities, and immunosuppression are associated with more severe disease [3], however, it is not clearly defined if patients with multiple sclerosis (MS) and neuromyelitis spectrum disorders (NMOSD) are at an increased risk of COVID-19 infection or at a higher risk of a more severe disease; therefore, the COVID-19 pandemic holds additional source of concern among Neurologists [4-6]. It is believed that patients with MS are at greater risk of admission in Intensive Care Unit (ICU) in case of any infection [7-9], this stems from the fact that these patients are on disease-modifying therapies (DMTs), as well as corticosteroid therapy during their attacks, which make them more immunocompromised [3]. DMTs are divided into two categories; immunomodulators and immunosuppressants [7, 10]. Evidence has demonstrated the direct or indirect role of B cells in the pathogenesis of both MS and NMO diseases $[11,12]$. In this regard, Anti-CD20 monoclonal antibodies (mAbs) targeting CD20, as Bcell-depleting therapies, have been demonstrated to reduce disease activity in both diseases [13-15]. These treatment options have been suggested as current immunosuppressive disease modifying therapies (DMTs) $[3,16]$. Particularly, Rituximab (RTX), a chimeric monoclonal antibody directed at CD20 positive B lymphocytes is considered a selective immunosuppressant used in different in clinical practice (500-1000 mg, every 3-6 months, or on demand at B cells detection of $\geq 2 \%$ of $B$ cells) $[7-10,17]$. Recent real- world experiences have shown that patients with either NMO or MS disease benefit efficiently from RTX with favorable safety and cost-effectiveness profile [17-20]. However, It has been suggested that the risk of serious infection for patients with MS or NMOSD varies depending on the DMTs being used. More efficient DMTs such as Rituximab might be associated with a higher risk of infection [8,9] but some authorities are against this assumption $[3,21]$ causing uncertainties over the safety of anti-CD20 antibodies during COVID-19 pandemic [3, 21]. The incidence rate of COVID-19 infection and the course of the illness among patients using Rituximab during the outbreak is still undefined due to scarce data, while current guidelines do not provide definitive recommendations $[4,22]$. Therefore, it is crucial to conduct a study to collect information in order to evaluate the clinical status of these patients and to assess the epidemiological and clinical parameters of COVID-19 patients with MS or NMOSD undergoing treatment with Rituximab. This study, along with other ongoing studies will hopefully provide us with more definitive evidences in the context of COVID-19 disease and help authorities to finally implement appropriate strategies.

\section{Methods \\ Study population}

In this analytical case series study, patients diagnosed with MS or NMOSD who were referred to the 3 hospitals in Tehran at the time the first case of COVID-19 pneumonia was reported in February 2020 until October 2020 were assessed. Patients that received Rituximab therapy as a DMT and have received at least one full dose before the COVID-19 pandemic were included in the study while patients that received the first dose of Rituximab during the pandemic were excluded.

\section{Study design}

A web-based (online) questionnaire was used in collecting data from patients and or their caregivers. Initially, the investigators made their contact with these patients through a phone call and explained to them the purpose of the study as well as a detailed explanation on how the data will be collected. The link of the online questionnaire was then provided to the participants. Where needed, investigators were ready to help patients to fill the online-form step by step. In cases of unanswered phone calls, the researchers will try again to reach to the patient for 3 more times within the 24-h period, then, after that the patient will be considered non-responder/ missed data and was deleted from the analysis and in cases of demised patients, the corresponding caregiver will be responsible to fill-up the online questionnaire.

The online questionnaire is composed of 2 core sets of data;(1) the demographic and clinical characteristics of the disease process and (2) information related to COVID-19. Part one of the questionnaire, assessed the following parameters; age, gender, comorbidities (diabetes mellitus, hypertension, cardiovascular diseases, chronic respiratory diseases, chronic kidney diseases and malignancies), disease duration and patient-reported walking disability which was assessed with the use of the Expanded Disability Status Scale (EDSS). Also, in this part of the questionnaire, information such as; the total number of Rituximab infusions administered as well as delayed dosing schedule during the pandemic (extended interval dosing), any occurrence of relapse, relapse of symptoms and treatment plan (inpatient or outpatient) and the use of corticosteroids during the COVID-19 outbreak were collected.

The second part of the questionnaire contain questions related to COVID-19 disease that include; self-isolation, any previous close contact with COVID-19 patient and the presence of suggestive symptoms of COVID-19 infection since the start of the outbreak. 
Patients manifesting two of the most common symptoms of COVID-19; fever, cough, shortness of breath were considered suspicious. In addition, information regarding medical and laboratory history and their test results (positive/negative) were collected. Confirmed COVID-19 patients are those with positive RT-PCR assay of nasal and pharyngeal swab specimens or a spiral chest CT-scan indicative for COVID-19 infection as reported by a physician. Information regarding patient care management for COVID-19 positive such as hospitalization, ICU- admission or home based care and duration of hospital stay were included in this questionnaire, also, the severity of the illness which was divided into 3 categories based on the CDC guideline ${ }^{(16)}$; mild to moderate (treated at home with isolation, antibiotics and hydration), severe (requires hospitalization due to dyspnea and hypoxia) and critical condition (requires ICU admission due to respiratory failure, shock or multi-organ system dysfunction) and lastly, the final outcome of the disease (recover, discharged or expired) are all contained in this questionnaire. Favorable outcome indicates patient's recovery or discharge from the hospital while unfavorable outcome means that the patient has expired.

\section{Statistical analysis}

Quantitative statistics were described using means and standard deviations while qualitative data were reported by their frequencies. Case fatality ratio was calculated via the proportion of deaths from the COVID-19 disease compared to the total number of patients diagnosed with the condition.

\section{Ethical approval}

This study was approved by the Research Ethics Committee, Iran University of Medical Sciences (IUMS) having a Registration Code: 99-1-20-17,858.

\section{Results}

Of the 350 patients assessed through their medical records, 312 were considered eligible and were invited by telephone call to participate in the study. Response rate among eligible individuals was $(n=258,82.6 \%)$. Of these 312 patients, 168 were females (65.1\%) and 90 were males (34.9\%). The mean age was $41.31 \pm(18-36$ years old). Majority of the subjects reported no comorbidities (87.6\%), $196(75.9 \%)$ received more than 3 doses of rituximab and 184 (71.3\%) expressed that scheduled doses of injection were not delayed despite the pandemic. Of the $216(83.7 \%)$ participants who did not receive any corticosteroids during the pandemic, no relapse was reported, however, out of the $42(16.3 \%)$ patients who received corticosteroids, 6 patients (14.3\%) reported a relapse. Results are summarized in Table 1.
Based on the result of the survey, $87.2 \%$ followed selfisolation guidelines and 25 (9.6\%) subjects were considered suspected cases for COVID-19 and after further evaluation, 9 (3.4\%) of these patients were finally confirmed positive for corona virus. Patients are individually described on Table 2

Patients with confirmed COVID-19 diagnosis consisted of 4 males and 5 females with mean age of 49.22 years old without any comorbidities. No recent relapses or corticosteroids use was reported by confirmed cases. Six patients had followed self-isolation and four cases reported recent contact with COVID-19 cases (Table 3). Five confirmed cases of COVID-19 were admitted to the hospital of which 2 of these patients were admitted in ICU. The rest of the patients received home-based care. Two of the patients died from COVID-19. The Mortality ratio among patients admitted to hospital was $40 \%$.

Among the study population, the incidence rate of COVID-19 was $3.4 \%$. The ratio of mild to moderate illness was $44.4 \%$ and the ratio of serious COVID-19 illness was $55.5 \%$. The ratio of favorable outcome (cured/ discharged) was $77.7 \%$ and the case fatality ratio (CFR) was $22.2 \%$ [CI: $-0.049<p<0.494$ ] (Table 3).

Results of the study has indicated that age ( $P$-value: $0.530)$, disease duration ( $P$-value: 0.760$)$ and walking disability score ( $P$-value: 0.730$)$ have no correlation with the type of management patients received as an indicator of severity (Table 3 ).

\section{Discussion}

This is one of the first case series during the COVID-19 pandemic implying unfavorable results of using Rituximab during the pandemic.

In spite the fact that the majority of COVID-19 cases in this study experienced mild to moderate illness, the hospitalization rate $(55.5 \%)$ and the proportion of patients with critical conditions (22.2\%) who ended up in ICU in comparison to all confirmed COVID-19 cases are considered relatively high.

The current study has not made any comparison with other DMTs. The evidence is also scarce and controversial in this regard. However, the case fatality ratio (CFR) $(22.2 \%)$ and the mortality ratio of Covid-19 among hospitalized patients $(40 \%)$ in this study are much higher than those of previous reports in patients who were not receiving rituximab $[23,24]$. In their own studies, Rituximab was related to an increased rate of COVID-19 infection compared to other DMTs [23, 24]. In addition, it can be noticed from a review that Anti CD-20 therapy is linked with more hospitalizations (either ventilated or not) and more deaths in patients with COVID-19 infection compared to other therapies for multiple sclerosis. However, the number of not hospitalized patients was also higher [25]. 
Table 1 Descriptive Analysis of demographic and clinical data

\begin{tabular}{|c|c|c|}
\hline Parameter $(N)$ & Categories & Frequency (\%) \\
\hline \multirow[t]{2}{*}{ Gender (258) } & Female & $65.1 \%$ \\
\hline & Male & $34.9 \%$ \\
\hline \multirow[t]{2}{*}{ Comorbidities (258) } & Present & $12.4 \%$ \\
\hline & Absent & $87.6 \%$ \\
\hline \multirow[t]{3}{*}{ Disease duration (258) } & $<5$ years & $35.7 \%$ \\
\hline & $5-10$ years & $29.4 \%$ \\
\hline & $>10$ years & $34.9 \%$ \\
\hline \multirow[t]{6}{*}{ Walking disability (258) } & Fully ambulatory, self-sufficient, which represents EDSS 0-3 & $46.8 \%$ \\
\hline & Ambulatory for $500 \mathrm{~m}$ without aid/rest which represents EDSS 4-4.5 & $16.3 \%$ \\
\hline & Ambulatory for $200 \mathrm{~m}$ without aid/rest which represents EDSS 5 & $14.0 \%$ \\
\hline & $\begin{array}{l}\text { Intermittent or unilateral constant assistance which represents } \\
\text { EDSS 5.5-6 }\end{array}$ & $12.4 \%$ \\
\hline & $\begin{array}{l}\text { Constant bilateral assistance (canes, crutches, or braces) which } \\
\text { represents EDSS } 6.5\end{array}$ & $6.2 \%$ \\
\hline & restricted to wheelchair which represents EDSS 7 & $4.3 \%$ \\
\hline \multirow[t]{4}{*}{ Total Number of Rituximab injections (258) } & Once & $7.8 \%$ \\
\hline & Twice & $16.3 \%$ \\
\hline & 3 times & $14.7 \%$ \\
\hline & $>4$ times & $61.2 \%$ \\
\hline \multirow[t]{2}{*}{ Extended interval dosing (258) } & Yes & $28.7 \%$ \\
\hline & No & $71.3 \%$ \\
\hline \multirow[t]{2}{*}{ Relapse during the pandemic (258) } & Yes & $16.3 \%$ \\
\hline & No & $83.7 \%$ \\
\hline \multirow[t]{3}{*}{ Relapse management (42) } & Outpatient & $35.7 \%$ \\
\hline & Inpatient & $9.6 \%$ \\
\hline & Not treated & $54.7 \%$ \\
\hline \multirow[t]{2}{*}{ Recent corticosteroid use (42) } & Yes & $14.3 \%$ \\
\hline & No & $85.71 \%$ \\
\hline \multirow[t]{2}{*}{ self-isolation (258) } & Yes & $87.2 \%$ \\
\hline & No & $12.8 \%$ \\
\hline \multirow[t]{2}{*}{ Contact with COVID-19 Patients (258) } & Yes & $4.3 \%$ \\
\hline & Not Aware & $95.7 \%$ \\
\hline \multirow[t]{2}{*}{ Suspected Covid-19 infection (258) } & Yes & $9.7 \%$ \\
\hline & No & $90.3 \%$ \\
\hline \multirow{2}{*}{$\begin{array}{l}\text { Assessment of Covid-19 } \\
\text { (RT-PCR or Imaging) (258) }\end{array}$} & Performed & $8.5 \%$ \\
\hline & Not performed & $91.5 \%$ \\
\hline
\end{tabular}

On the contrary, it has been suggested in some few reports with a similar design to ours that this drug is not linked to a greater risk of serious complications of COVID-19 illness, and they encouraged using Rituximab in MS patients [3, 8, 26, 27] But one main limitation of the mentioned studies are the small sample size, not comparing with other DMTs, and lack of accurate COVID-19 confirmation [3].
Regarding predisposing factors, the sample size is insufficient for analysis, but an overview of the medical background of the infected cases shows that the majority of these patients have been treated with Rituximab for a minimum of 2 doses on a prompt and timely manner. Females were more infected than males but the male gender experienced more severe disease and had higher mortality rate. Recent exacerbation and corticosteroids 
Esmaeili et al. BMC Neurology

(2021) 21:183

Page 5 of 8

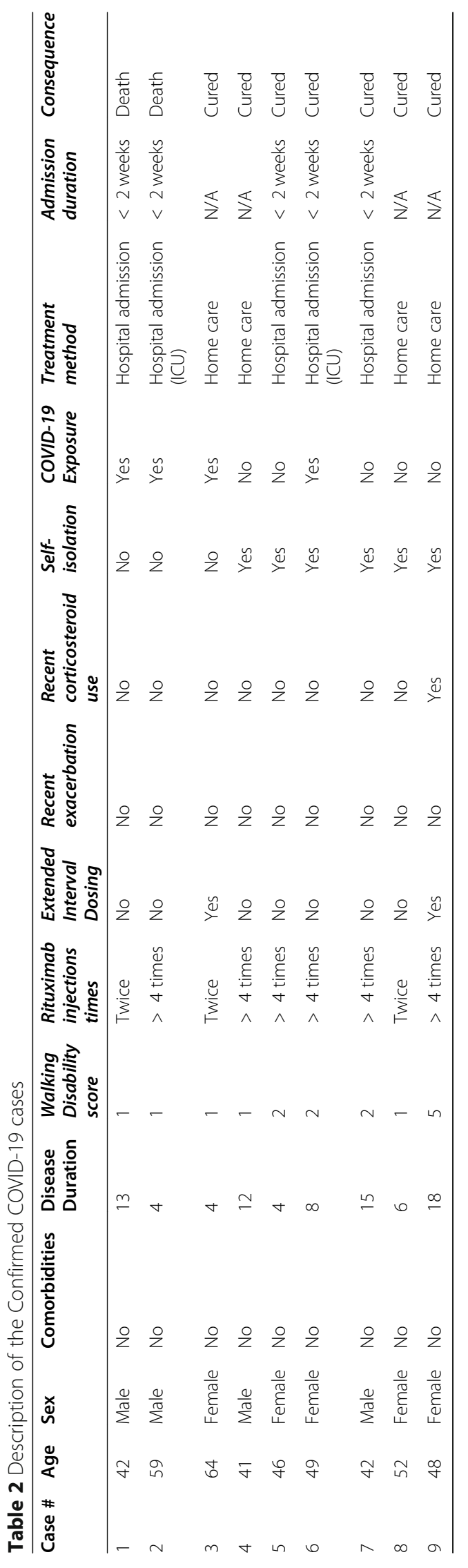


Table 3 Descriptive statistics of confirmed COVID-19 cases

\begin{tabular}{|c|c|c|c|c|}
\hline \multicolumn{2}{|c|}{ Parameter ((Mean \pm SD/ Q1,Median,Q3) or (\#\\
%)) } & \multicolumn{3}{|l|}{ Treatment strategy } \\
\hline & & Confirmed cases (9) & Home-based care (4) & Hospital admission (5) \\
\hline \multicolumn{2}{|l|}{ Age } & $49.22 \pm 7.94[41-64]$ & $51.25 \pm 9.63[41-64]$ & $47.6 \pm 7.02[42-59]$ \\
\hline \multicolumn{5}{|l|}{$P$-value ${ }^{\mathrm{a}}: 0.530^{\mathrm{b}}$} \\
\hline \multirow[t]{2}{*}{ Sex } & Male & $4(44.4 \%)$ & $1(25 \%)$ & $3(60 \%)$ \\
\hline & Female & $5(55.6 \%)$ & $3(75 \%)$ & $2(40 \%)$ \\
\hline \multicolumn{2}{|l|}{ Disease duration } & $9.33 \pm 5.31[4-18]$ & $10.00 \pm 6.32[4-18]$ & $8.80 \pm 5.06[4-15]$ \\
\hline \multicolumn{5}{|l|}{$P$-value ${ }^{a}: 0.760^{b}$} \\
\hline \multicolumn{2}{|l|}{ Walking disability } & $1.78 \pm 1.30[1-5]$ & $2.00 \pm 2.00$ & $1.6 \pm 0.54$ \\
\hline \multicolumn{5}{|l|}{$P$-value ${ }^{a}: 0.730^{c}$} \\
\hline \multirow[t]{4}{*}{ Number of Rituximab injections so far } & Once & $0(0 \%)$ & $0(0 \%)$ & $0(0 \%)$ \\
\hline & Twice & $3(33.3 \%)$ & $2(50 \%)$ & $1(20 \%)$ \\
\hline & Thrice & $0(0 \%)$ & $0(0 \%)$ & $0(0 \%)$ \\
\hline & $>4$ doses & $6(66.6 \%)$ & $2(50 \%)$ & $4(80 \%)$ \\
\hline \multirow[t]{2}{*}{ Extended Interval Dosing } & Positive & $2(22.2 \%)$ & $2(50 \%)$ & $1(20 \%)$ \\
\hline & Negative & $7(77.7 \%)$ & $2(50 \%)$ & $4(80 \%)$ \\
\hline \multirow[t]{2}{*}{ Comorbidity } & Positive & $0(0 \%)$ & $0(0 \%)$ & $0(0 \%)$ \\
\hline & Negative & $9(100 \%)$ & $4(100 \%)$ & $5(100 \%)$ \\
\hline \multirow[t]{2}{*}{ Recent relapse } & Positive & $0(0 \%)$ & $0(0 \%)$ & $0(0 \%)$ \\
\hline & Negative & $9(100 \%)$ & $4(100 \%)$ & $5(100 \%)$ \\
\hline \multirow[t]{2}{*}{ Corticosteroids consumption } & positive & $1(11.1 \%)$ & $1(25 \%)$ & $0(0 \%)$ \\
\hline & Negative & $8(88.8 \%)$ & $3(75 \%)$ & $5(100 \%)$ \\
\hline \multirow[t]{2}{*}{ self-isolation } & Positive & $6(66.6 \%)$ & $3(75 \%)$ & $3(60 \%)$ \\
\hline & Negative & $3(33.3 \%)$ & $1(25 \%)$ & $2(40 \%)$ \\
\hline \multirow[t]{2}{*}{ COVID-19 contact } & Positive & $4(44.4 \%)$ & $1(25 \%)$ & $4(80 \%)$ \\
\hline & Negative & $5(55.5 \%)$ & $3(75 \%)$ & $1(20 \%)$ \\
\hline \multirow[t]{2}{*}{ Final outcome } & Cured/Discharged & $7(77.7 \%)$ & $4(100 \%)$ & $3(60 \%)$ \\
\hline & Death & $2(22.2 \%)$ & $0(0 \%)$ & $2(40 \%)$ \\
\hline Incidence Rate & Mild to Moderate Condition & Serious Condition & Case Fatality Rate & \\
\hline $3.4 \%$ & $44.4 \%$ & $11 \%$ & $22.2 \%$ & \\
\hline
\end{tabular}

${ }^{a}$ : Comparison between treatment strategies which were finally required for patient's management; ${ }^{\mathrm{b}}$ : Student T-test; ${ }^{\mathrm{c}}$ : Mann-Whitney U test

use were mostly negative and walking disability was less than 3 in most cases. Based on our findings, majority of the study population were extremely health conscious as indicated by the high percentage (96\%) of patients observing strict self-isolation and promptly responded to potential symptoms of coronavirus. As noted, both patients who died of COVID-19 had not followed social distancing recommendations and had been exposed to a person with COVID-19.

To explain the results, it is believed that the $\mathrm{T}$ cell immunity is vital for the control of SARS-CoV-2 infection [28]. In particular, it has been shown that decrease in percentage of CD8 T-lymphocytes, and not CD4 cells, is associated with poor outcome [29]. But, the immunity against COVID-19 is complex and current studies show B-cell responses occur concomitantly in patients infected with COVID-19 disease, and most patients develop neutralizing antibodies after a delay, which are likely to be effective against SARS-CoV-2 with good clinical results [30]. Above all, some studies have demonstrated that Rituximab can also make a reduction in T-lymphocytes, especially in $\mathrm{CD} 3+, \mathrm{CD} 4+$, and to a lesser degree CD8+ $\mathrm{T}$-cells along with a small subgroup of $\mathrm{T}$-cells expressing CD20 [31]. This might justify the higher risk of serious viral infections in susceptible patients [32]. However, it is controversial whether it causes further decrease in repeated cycles of use [33] or not [34].

Regarding the general approach of using DMTs during the pandemic, recommendations are categorized into initiation, continuing, delaying, and stopping DMTs. The International Federation (MSIF) along with MS Society have recommended not to initiate Rituximab 
during the COVID-19 pandemic, but the Global advice for MS patients during pandemic does not suggest Rituximab discontinuation. Delaying the next doses of Rituximab should be individualized and based on patient-physician shared decision making (SDM) [3537] In this respect, Dr. Brownlee [38] has endorsed delaying the initiation of Rituximab or considering an alternative for patients along with extended interval dosing guided by intermittent assay for CD19 lymphocyte counts for patients already on treatment. In our study, since none of the confirmed COVID-19 patients who were seriously ill had experienced delayed scheduled infusion dates, we cautiously recommend extended interval dosing if there is an immediate need for doing so.

Regarding NMOSD, discontinuation or using extended-interval dosing in these patients is discouraged, for the reason that withholding or delaying high efficacy DMTs might conversely place patients at a higher risk of relapse, which in turn results in ominous consequences. This may as well increase the chance of serious COVID19 illness indirectly since it is hypothesized that higher EDSS scores result in less mobility and worsens the COVID-19 disease outcome [7, 37]. Altogether, thorough medical judgment including risk assessment of delaying the treatment should be decided individually and watchful surveillance is suggested.

The strong point of our study is utilization of either positive PCR or Chest CT results for verifying COVID19 diagnosis to avoid missing cases. The limitation of this study is not comparing these patients with those being treated with other DMTs. In addition, evaluating outcomes in patients with extended interval dosing regimen is recommended in future observational studies, considering as well previous and concomitant treatments if COVID-19 is confirmed.

\section{Conclusion}

Patients with MS or NMOSD being treated with Rituximab may be at an increased risk of COVID-19 infection and higher possibility of serious illness and mortality. The idea of extended interval dosing during the pandemic is encouraged and the important role of selfisolation and not being exposed to patients with COVID-19 is suggested.

\section{Abbreviations}

MS: Multiple sclerosis; NMOSD: Neuromyelitis spectrum disorders;

RTX: Rituximab; EDSS: Expanded Disability Status Scale

\section{Acknowledgments}

We wish to express our gratitude to Maryam Daneshgar for the professional English edition. We would like to appreciate Dr.S. Monica, Dr. F. Faghihi, Dr. F.H. Akhondi and Dr. S.H. Fesharaki for their support.

\section{Authors' contributions}

Sara Esmaeili: Conceptualization, Methodology, Investigation, Writing -

Original Draft, Writing - Review \& Editing, Project administration. Mohammad
Hossein Abbasi: Conceptualization, Formal analysis, Investigation, Writing Original Draft, Writing - Review \& Editing, Meysam Abolmaali: Investigation, Writing - Original Draft, Writing - Review \& Editing, Mohammad Mojtahed: Methodology, Validation, Investigation, Writing - Original Draft, Writing Review \& Editing. Seyedeh Niloufar Rafiei Alavi: Methodology, Investigation, Writing - Original Draft, Writing - Review \& Editing. Sevim Soleimani: Methodology, Investigation, Writing - Original Draft, Writing - Review \& Editing. Mahisa Mokhtari: Methodology, Investigation, Writing - Original Draft, Writing - Review \& Editing. Jaber Hatam: Methodology, Investigation, Writing - Original Draft, Writing - Review \& Editing. Samaneh Tanhapour khotbehsara: Methodology, Investigation, Writing - Original Draft, Writing - Review \& Editing. Mohammad Reza Motamed: Methodology, Investigation, Writing Original Draft, Writing - Review \& Editing. Mohammad Taghi Joghataei: Methodology, Validation, Writing - Review \& Editing, Supervision. Zahra Mirzaasgari: Conceptualization, Methodology, Validation, Writing - Review \& Editing, Supervision, Project administration. Mehdi Moghaddasi: Methodology, Validation, Writing - Review \& Editing, Supervision, Project administration. The author(s) read and approved the final manuscript.

\section{Funding}

This study did not receive any specific grant from any companies, funding agencies in the public, commercial, or not-for-profit sectors.

\section{Availability of data and materials}

The datasets used and/or analyzed during the current study are available from the corresponding author on reasonable request.

\section{Declarations}

Ethics approval and consent to participate

All methods and experimental protocols were carried out in accordance with relevant guidelines and regulations and were approved by the Research Ethics Committee of the Iran University of Medical Sciences (IUMS) (Registration Code: 99-1-20-17858). Informed consent was obtained from all subjects to use the information they give us through electronic questionnaires.

\section{Consent for publication}

Not applicable.

\section{Competing interests}

The Authors declare that they have no conflict of interest.

\section{Author details}

${ }^{1}$ Cellular and Molecular Research Center, Iran university of medical sciences, Tehran, Iran. ${ }^{2}$ School of Advanced Technologies in Medicine, Iran University of Medical Sciences, Tehran, Iran. ${ }^{3}$ Department of Neurology, Iran University of Medical Sciences, Tehran, Iran. ${ }^{4}$ School of Medicine, Shahid Beheshti Medical University, Tehran, Iran. ${ }^{5}$ Department of Neurosurgery, Iran University of Medical Sciences, Tehran, Iran.

Received: 29 November 2020 Accepted: 26 April 2021

Published online: 01 May 2021

\section{References}

1. Li H, Liu SM, Yu XH, Tang SL, Tang CK. Coronavirus disease 2019 (COVID-19): current status and future perspectives. Int J Antimicrob Agents. 2020; 105951.

2. Severo Bem Junior $L$, do Rego Aquino PL, Nunes Rabelo $N$, do Rego Aquino MA, Veiga Silva AC, Ferreira Valenca Mota RdC, Rocha Cirne de Azevedo Filho H: SARS-CoV-2 and Nervous System - Neurological Manifestations in Patients With COVID-19: A Systematic Review; 2020.

3. Giovannoni G. Anti-CD20 immunosuppressive disease-modifying therapies and COVID-19. Multiple sclerosis and related disorders. 2020;41:102135. https://doi.org/10.1016/j.msard.2020.102135.

4. Coles A. Abn guidance on the use of disease-modifying therapies in multiple sclerosis in response to the threat of a coronavirus epidemic. Association of British Neurologists. 2020;2020.

5. E Waubant MS: world-wide phone conference. International Federation of Women in MS. 
6. Naser Moghadasi A, Azadvari M, Sahraian MA: Rehabilitation Recommendations for Multiple Sclerosis Patients during the COVID-19 Pandemic. 2020, 23(7):509-510.

7. Brownlee W, Bourdette D, Broadley S, Killestein J, Ciccarelli O. Treating multiple sclerosis and neuromyelitis optica spectrum disorder during the COVID-19 pandemic. Neurology. 2020;94(22):949-52. https://doi.org/1 0.1212 WNL.0000000000009507.

8. Sormani MP. An Italian programme for COVID-19 infection in multiple sclerosis. Lancet Neurology.

9. Wijnands JM, Kingwell E, Zhu F, Zhao Y, Fisk JD, Evans C, et al. Infectionrelated health care utilization among people with and without multiple sclerosis. Mult Scler. 2017;23(11):1506-16. https://doi.org/10.1177/135245851 6681198.

10. Filippini G, Del Giovane C, Vacchi L, D'Amico R, Di Pietrantonj C, Beecher D, et al. Immunomodulators and immunosuppressants for multiple sclerosis: a network meta-analysis. Cochrane database Syst Rev. 2013;6:CD008933.

11. Krumbholz M, Meinl E. B cells in MS and NMO: pathogenesis and therapy. Semin Immunopathol. 2014;36(3):339-50. https://doi.org/10.1 007/s00281-014-0424-x.

12. Häusser-Kinzel S, Weber MS. The Role of B Cells and Antibodies in Multiple Sclerosis, Neuromyelitis Optica, and Related Disorders. Front Immunol. 2019;10:201.

13. D'Amico E, Zanghì A, Gastaldi M, Patti F, Zappia M, Franciotta D. Placing CD20-targeted B cell depletion in multiple sclerosis therapeutic scenario: present and future perspectives. Autoimmun Rev. 2019;18(7):665-72. https:// doi.org/10.1016/j.autrev.2019.05.003.

14. Gelfand JM, Cree BAC, Hauser SL. Ocrelizumab and other CD20+ B-celldepleting therapies in multiple sclerosis. Neurotherapeutics. 2017;14(4):83541. https://doi.org/10.1007/s13311-017-0557-4.

15. Graf J, Mares J, Barnett M, Aktas O, Albrecht P, Zamvil SS, Hartung HP: Targeting B Cells to Modify MS, NMOSD, and MOGAD. Part 12021 , 8(1):e918

16. Chisari CG, Sgarlata E, Arena S, Toscano S, Luca M, Patti F. Rituximab for the treatment of multiple sclerosis: a review. J Neurol. 2021. https://doi.org/10.1 007/s00415-020-10362-z.

17. D'Amico E, Zanghì A, Chisari CG, Fermo SL, Toscano S, Arena S, et al. Effectiveness and safety of rituximab in demyelinating diseases spectrum: an Italian experience. Multiple sclerosis and related disorders. 2019;27:324-6. https://doi.org/10.1016/j.msard.2018.09.041.

18. Airas L, Nylund M, Mannonen I, Matilainen M, Sucksdorff M, Rissanen E. Rituximab in the treatment of multiple sclerosis in the Hospital District of Southwest Finland. Multiple sclerosis and related disorders. 2020;40:101980. https://doi.org/10.1016/j.msard.2020.101980.

19. Hellgren J, Risedal A, Kallen K. Rituximab in multiple sclerosis at general hospital level. Acta Neurol Scand. 2020:141.

20. Salzer J, Svenningsson R, Alping P, Novakova L, Björck A, Fink K, et al. Rituximab in multiple sclerosis: a retrospective observational study on safety and efficacy. Neurology. 2016;87(20):2074-81. https://doi.org/10.1212/WNL. 0000000000003331

21. Giovannoni G, Hawkes C, Lechner-Scott J, Levy M, Waubant E, Gold J. The COVID-19 pandemic and the use of MS disease-modifying therapies. Multiple Sclerosis Related Disorders. 2020;39:102073. https://doi.org/10.1016/ j.msard.2020.102073.

22. E Waubant MS: MS Treatment Guidelines During Coronavirus.

23. Nikpouraghdam M, Jalali Farahani A, Alishiri G, Heydari S, Ebrahimnia M, Samadinia $\mathrm{H}$, et al. Epidemiological characteristics of coronavirus disease 2019 (COVID-19) patients in IRAN: a single center study. J Clin Virology. 2020;127:104378. https://doi.org/10.1016/j.jcv.2020.104378.

24. Sahraian MA, Azimi A, Navardi S, Ala S, Naser Moghadasi A. Evaluation of the rate of COVID-19 infection, hospitalization and death among Iranian patients with multiple sclerosis. Multiple Sclerosis Related Disorders. 2020;46: 102472. https://doi.org/10.1016/j.msard.2020.102472.

25. Möhn N, Konen FF, Pul R, Kleinschnitz C, Prüss H, Witte T, et al. Experience in Multiple Sclerosis Patients with COVID-19 and Disease-Modifying Therapies: A Review of 873 Published Cases. J Clin Med. 2020;9:12.

26. Montero-Escribano P, Matías-Guiu J, Gómez-Iglesias P, Porta-Etessam J, Pytel V, Matias-Guiu JA. Anti-CD20 and COVID-19 in multiple sclerosis and related disorders: a case series of 60 patients from Madrid, Spain. Multiple sclerosis and related disorders. 2020;42:102185. https://doi.org/10.1016/j.msard.2020.102185.

27. Safavi F, Nourbakhsh B, Azimi AR. B-cell depleting therapies may affect susceptibility to acute respiratory illness among patients with multiple sclerosis during the early COVID-19 epidemic in Iran. Multiple Sclerosis Related Dis. 2020:43:102195. https://doi.org/10.1016/j.msard.2020.102195.

28. Nelde A, Bilich T, Heitmann JS, Maringer $Y$, Salih HR, Roerden M, et al. SARSCoV-2-derived peptides define heterologous and COVID-19-induced T cell recognition. Nat Immunol. 2021;22(1):74-85. https://doi.org/10.1038/s41590020-00808-x.

29. Urra JM, Cabrera CM, Porras L, Ródenas I. Selective CD8 cell reduction by SARS-CoV-2 is associated with a worse prognosis and systemic inflammation in COVID-19 patients. Clinical immunology (Orlando, Fla). 2020;217:108486.

30. Jacobs JJL. Neutralizing antibodies mediate virus-immune pathology of COVID-19. Med Hypotheses. 2020;143:109884. https://doi.org/10.1016/j. mehy.2020.109884

31. Palanichamy A, Jahn S, Nickles D, Derstine M, Abounasr A, Hauser SL, et al. Rituximab Efficiently Depletes Increased CD20-Expressing T Cells in Multiple Sclerosis Patients. J Immunol. 2014;193(2):580-6.

32. Hardeman P, Mann M, Hughes S, Greenberg B: Does Rituximab Cause Depletion of T-Cells in Multiple Sclerosis and Neuromyelitis Optica? (P2.158). 2016, 86(16 Supplement):P2.158.

33. Luna G, Alping P, Burman J, Fink K, Fogdell-Hahn A, Gunnarsson M, et al. Infection Risks Among Patients With Multiple Sclerosis Treated With Fingolimod, Natalizumab, Rituximab, and Injectable Therapies. JAMA Neurology. 2019;77:2.

34. Lavielle M, Mulleman D, Goupille $P$, Bahuaud C, Sung HC, Watier $H$, et al. Repeated decrease of CD4+ T-cell counts in patients with rheumatoid arthritis over multiple cycles of rituximab treatment. Arthritis Research \& Therapy. 2016;18(1):253. https://doi.org/10.1186/s13075-016-1152-5.

35. Maarouf A, Rico A, Boutiere C, Perriguey M, Demortiere S, Pelletier J, Audoin $B$ : Extending rituximab dosing intervals in patients with MS during the COVID-19 pandemic and beyond? 2020, 7(5):e825.

36. Korsukewitz C, Reddel SW, Bar-Or A, Wiendl H. Neurological immunotherapy in the era of COVID-19 - looking for consensus in the literature. Nat Rev Neurol. 2020;16(9):493-505. https://doi.org/10.1038/s41582-020-0385-8.

37. Ricardo A, Carnero Contentti E, Anabel SB, Adrian LP, Orlando G, Fernando $\mathrm{H}$, et al. Decision-making on management of ms and nmosd patients during the COVID-19 pandemic: a latin american survey. Multiple sclerosis and related disorders. 2020;44:102310. https://doi.org/1 0.1016/j.msard.2020.102310.

38. Brownlee WJ. COVID-19 and high-efficacy multiple sclerosis therapies: Time for business as usual? Mult Scler. 2020;26(10):1267-7.

\section{Publisher's Note}

Springer Nature remains neutral with regard to jurisdictional claims in published maps and institutional affiliations.

Ready to submit your research? Choose BMC and benefit from:

- fast, convenient online submission

- thorough peer review by experienced researchers in your field

- rapid publication on acceptance

- support for research data, including large and complex data types

- gold Open Access which fosters wider collaboration and increased citations

- maximum visibility for your research: over $100 \mathrm{M}$ website views per year

At $\mathrm{BMC}$, research is always in progress.

Learn more biomedcentral.com/submissions 